\title{
THE COMPARATIVE EFFECTS OF SMALL INTRAVENOUS DOSES OF L-NOR- EPINEPHRINE UPON ARTERIAL PRESSURE AND PULSE RATE IN NOR- MOTENSIVE SUBJECTS AND IN HYPERTENSIVE PATIENTS BEFORE AND AFTER THORACOLUMBAR SYMPATHECTOMY
}

\author{
By WALTER E. JUDSON, FRANKLIN H. EPSTEIN, AND ROBERT W. WILKINS \\ (From the Robert Dawson Evans Memorial, Massachusetts Memorial Hospitals, and the De- \\ partment of Medicine, Boston University School of Medicine, Boston)
}

(Submitted for publication May 13, 1950; accepted, July 24, 1950)

\section{INTRODUCTION}

The original observations by Oliver and Shafer of marked pressor effects occurring in animals after the intravenous injection of extracts of the adrenal medulla emphasized the biological importance of these substances (1). Later, Elliott concluded that epinephrine is involved in sympathetic nervous transmission of adrenergic effects and speculated upon its release at sympathetic nerve endings (2). In 1910, Barger and Dale suggested that not only epinephrine, but also other related sympathomimetic pressor amines might be released at sympathetic nerve endings and mediate various physiologic responses (3). Then, Loewi, in a series of brilliantly executed experiments, demonstrated that stimulation of sympathetic nerves containing adrenergic fibers to the frog's heart resulted in the release of adrenaline $(4,5)$. In 1946, von Euler found in animals a nor-epinephrine-like substance present in various tissues and organs containing adrenergic fibers (6). The recent chemical isolation by Tullar of the 1-isomer of nor-epinephrine from the racemic mixture of the drug ( 7 ) led to the demonstration by Luduena that this isomer is physiologically 27 to 60 times more active than the d-isomer (8). The subsequent detection of this substance in natural lots of epinephrine (9) and in extracts of adrenal medullary tumors (pheochromocytomas) $(10,11)$ stimulated a renewal of interest in its pharmacologic and hemodynamic actions, especially as they might relate to the problem of arterial hypertension.

In a hemodynamic study in man Goldenberg and his co-workers found that the vasoconstrictor effects produced by intravenous 1-nor-epinephrine were blocked by equal doses of intravenous epinephrine (12). They found that in normotensive subjects 1-nor-epinephrine produced a hypertension similar to "essential hypertension" with an increase in total peripheral resistance, but no change in cardiac output. Epinephrine, on the other hand, induced a hypertension with an increase in cardiac output and a decrease in total peripheral resistance. In patients with essential hypertension 1-nor-epinephrine produced a significantly greater vasopressor response than in normotensive subjects, as judged by statistical analyses of the absolute rises in systolic and mean arterial pressure. Moreover, the reflex slowing of the pulse rate normally associated with rises in arterial pressure was frequently absent in hypertensive patients. Goldenberg suggested that the increased sensitivity of hypertensive patients to infusions of 1-nor-epinephrine might be "due to lack of an antagonistic factor, epinephrine, in the peripheral nerve endings."

Since a previous study in this laboratory of the effects of commercial epinephrine given in single small intravenous doses failed to reveal an abnormal sensitivity to this drug in hypertensive patients either before or after lumbodorsal splanchnicectomy (13), it was decided to carry out a similar investigation with l-nor-epinephrine.

\section{MATERIALS AND METHODS}

The subjects were patients admitted to the Medical and Surgical wards of the Massachusetts Memorial Hospitals. The methods used in this investigation were essentially the same as those described in a previous communication (13). Intermittent single doses of 1-nor-epinephrine ${ }^{1}$ diluted in normal saline solution were administered intravenously. The dosage varied from 0.25 to 15 micrograms $(.00000025$ to $.000015 \mathrm{gm}$.), the volume from 0.25 to $5 \mathrm{ml}$., and the

1 Levo-Arterenol, L. A. 4802-V. Winthrop-Stearns, Inc. $1 \mathrm{ml} .=1.88 \mathrm{mg}$. 1-Arterenol bitartrate $=1 \mathrm{mg}$. 1-Arterenol base. 
BEFORE OPERATION

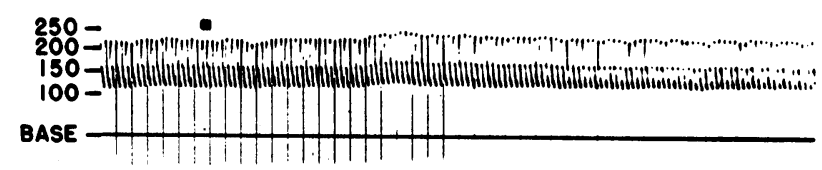

\section{ARTERIAL PRESSURE \\ MM HG}

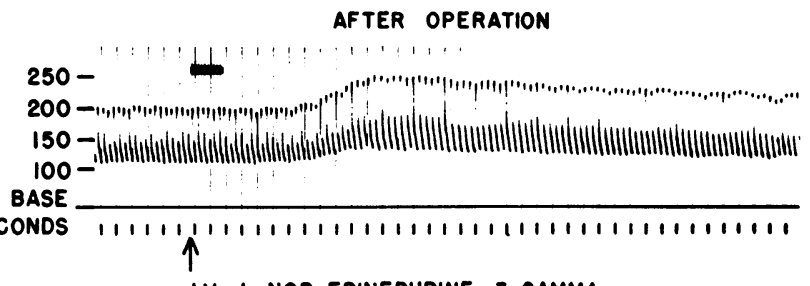

INTERVALS 2 SECONDS 11111,111111111111111111111111111111

I.V. L-NOR-EPINEPHRINE 3 GAMMA

Fig. 1. Optical Record of Brachial Intra-Arterial Pressure (Sanborn Electromanometer) Showing the Response to an Intravenous Injection of 3 Micrograms of L-Nor-Epinephrine in a Hypertensive Patient Before and After Thoracolumbar Sympathectomy

While the pressor response to the drug was definitely greater after operation, the apparent difference is much exaggerated by the greater sensitivity of the manometer used in the postoperative test.

time of injection from one to five seconds. These studies were carried out in five normotensive subjects and in six hypertensive patients, who were tested before operation and again at least ten days after the completion of the second stage of a thoracolumbar sympathectomy.

\section{RESULTS}

Figure 1 shows electromanometer tracings of the typical hemodynamic responses of a hypertensive patient before and after thoracolumbar sympathectomy to a small intravenous dose of 1-norepinephrine. It is seen that approximately 20 to 25 seconds after the injection of 3 micrograms of the drug a hypertensive response occurred with a sharp rise in both systolic and diastolic pressures. This hypertensive response represents the characteristic reaction found after small single doses of 1-nor-epinephrine. It generally persisted from 30 to 90 seconds, depending somewhat upon the magnitude of the dosage. At least two minutes were allowed to elapse for the blood pressure and pulse rate to return to control levels before a subsequent dose was injected. Control injections of saline produced no response. In contrast to the moderately severe subjective symptoms such as throbbing in the head, chest or abdomen, marked palpitation, dyspnea, and occasional emotional outbursts produced in patients by intravenous injections of regular epinephrine, comparable doses of 1-nor-epinephrine administered in the same manner caused virtually no symptoms except for an occasional, transient, ill-defined tightness of the chest or head, slight throbbing in the head, and rarely, fleeting dyspnea.

There were no qualitative differences in the blood pressure responses of the normotensive sub-

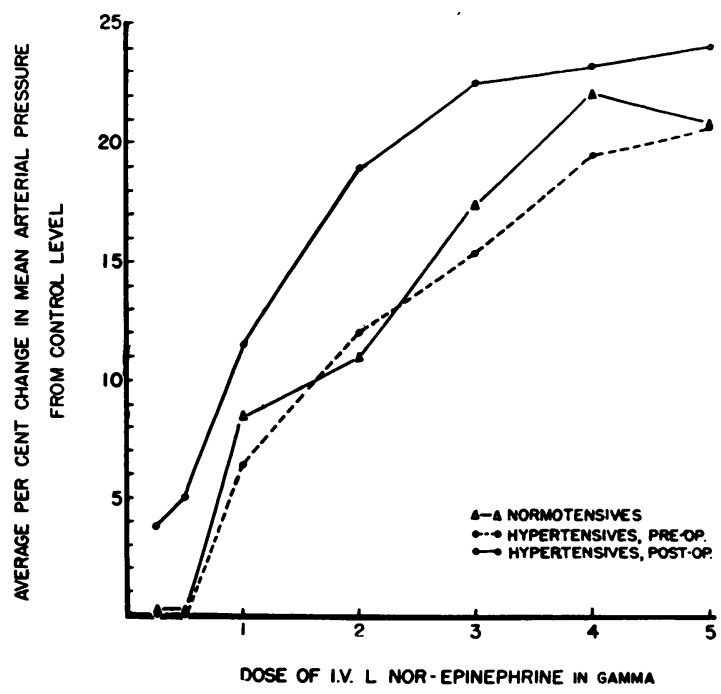

Fig. 2. Graph Showing the Average Percentile Changes of Mean Arterial Pressure in the Different Groups of Patients after Various Intravenots Doses OF L-Nor-EPINEPHRINE 







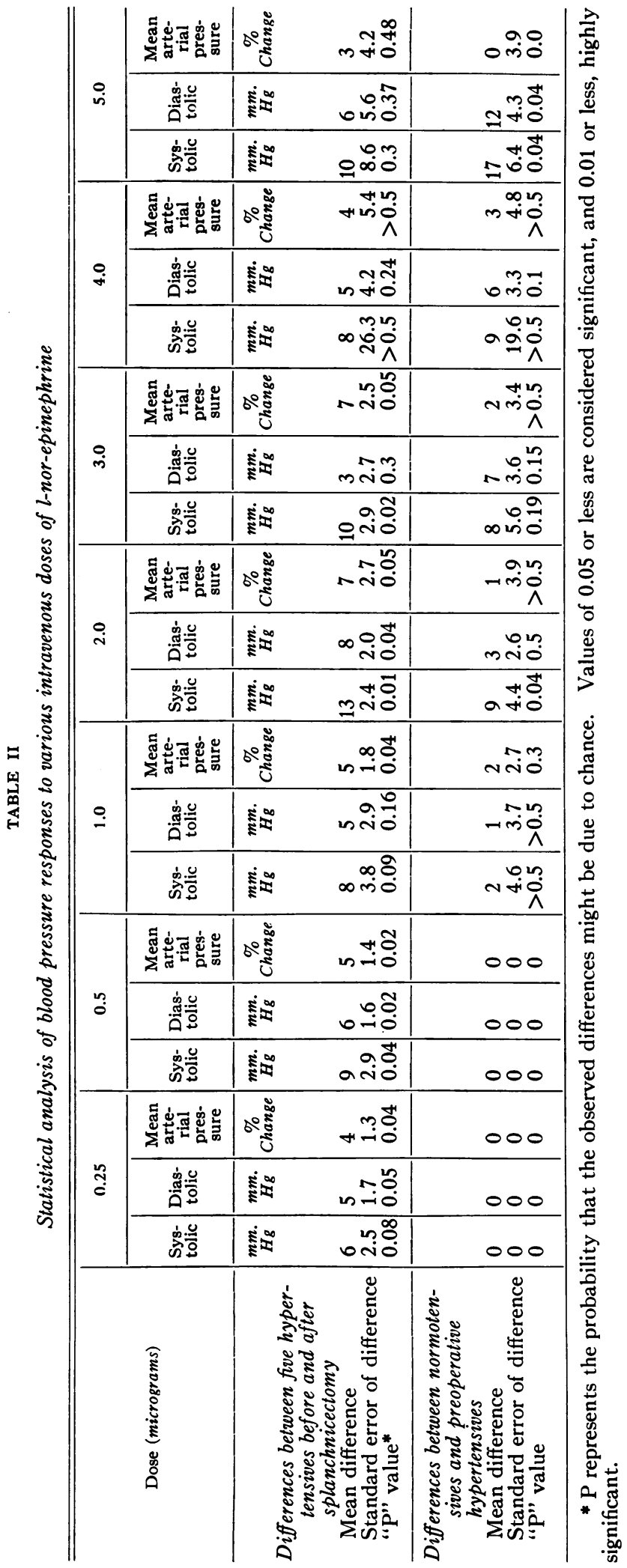


jects and the preoperative hypertensive patients. Likewise, after thoracolumbar sympathectomy, hypertensive patients did not manifest any striking differences in their blood pressure responses as compared with those of the other two groups (Figure 1). Figure 2 illustrates the average per cent change (from control level) of the mean arterial pressure of the different groups after various doses of intravenous 1-nor-epinephrine. Careful measurements and complete statistical analyses were made of the absolute and percentile changes in systolic, diastolic, and mean arterial pressures (Tables I and II). In the smaller range of dosage (from 0.25 to 3 micrograms) the hypertensive patients after sympathectomy usually showed a greater percentile increase in mean arterial blood pressure, as well as in absolute systolic and diastolic pressures, than they did before operation $\left(\mathrm{P}^{2}\right.$ greater than 0.01 and less than 0.05$)$. These differences were not apparent in all patients; and as the magnitude of the dosage was increased, the differences in blood pressure response became less marked or disappeared completely. One hypertensive patient, studied three years after lumbodorsal splanchnicectomy, showed no striking differences in degree of sensitivity to l-norepinephrine as compared with the other hypertensive patients or the normotensive control subjects.

$\because \mathrm{P}$ represents the probability that the observed difference might be due to chance. Values of 0.05 or less are considered significant, and 0.01 or less, highly significant.

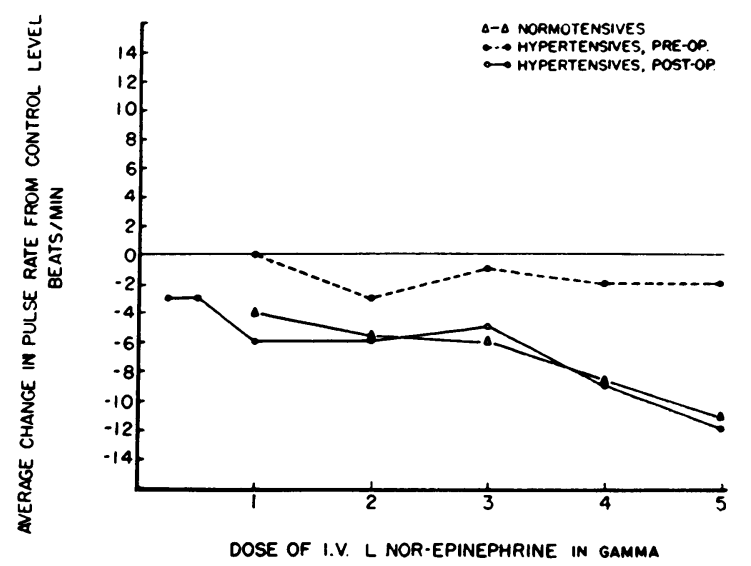

Fig. 3. Graph Showing the Average Changes in Pllse Rate in the Different Groups of Patients after Variols Intravenous Doses of L-Nor-EpinephRINE
Since a previous study of the effects of intravenous epinephrine revealed an interesting failure of the pulse rate to slow normally in preoperative hypertensive patients during the pressor phases of the response, similar comparisons were made between the changes in pulse rate in the different groups of patients after various intravenous doses of 1-nor-epinephrine (Figure 3). These showed that the normotensive subjects decreased their pulse rates after the intravenous administration of 1-nor-epinephrine. By contrast, the hypertensive patients before operation either maintained or decreased their pulse rates only slightly during their hypertensive responses to intravenous 1-nor-epinephrine, whereas after splanchnicectomy the same patients conformed more to the normotensive pattern and significantly slowed their pulse rates. Although it had already been found that some postoperative hypertensive patients had significantly greater blood pressure responses to small doses of 1-nor-epinephrine, the differences in their pulse rate changes could not be explained solely as due to this factor (elevation of blood pressure), since it was not consistently greater throughout the entire range of dosage.

The resting mean arterial pressure usually was moderately lowered in the hypertensive patients after splanchnicectomy. However, the differences in response of their pulse rates to intravenous 1-nor-epinephrine after operation could not be attributed to differences in the levels of their resting arterial pressure (Figure 4). In a few hypertensive patients during and immediately after the pressor response to intravenous 1-nor-epinephrine bursts of premature ventricular contractions occurred which limited further increases in dosage.

\section{DISCUSSION}

An important factor proposed for the initiation of arterial hypertension by adherents to the neurogenic theory is that stimulation of the autonomic nervous system results in liberation of chemical substances which cause vasoconstriction of the arterioles. The isolation of endogenous nor-epinephrine from the human body and the additional evidence that it produces an increased peripheral resistance and other hemodynamic responses resembling those found in essential hypertension have stimulated several workers to speculate on its relative importance in human hypertension. 


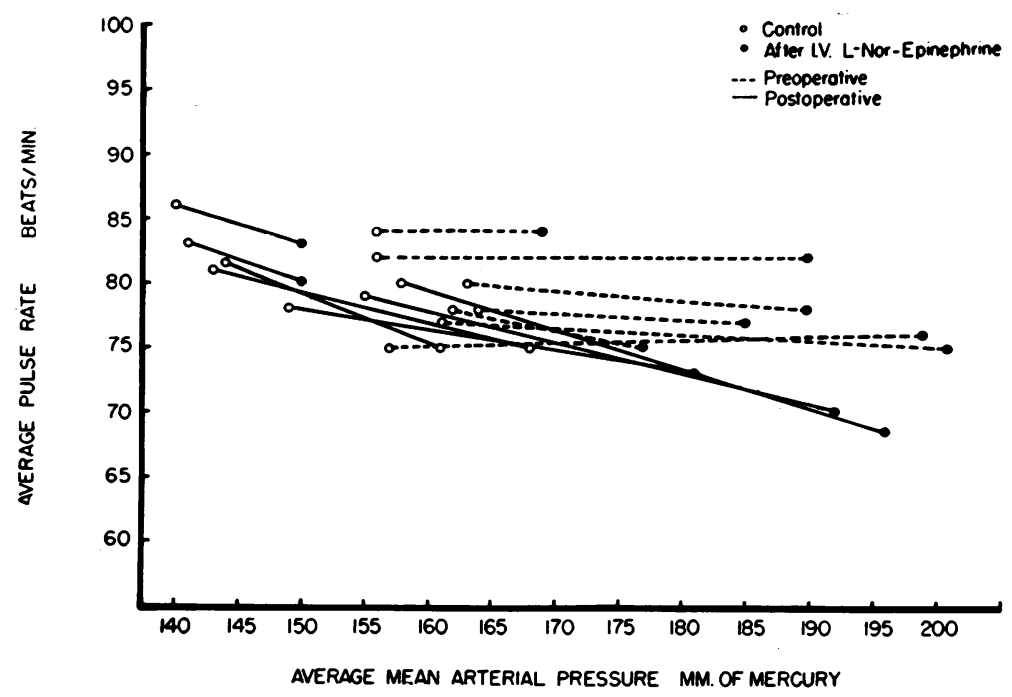

Fig. 4. Graph Showing the Average Pulse Rates, and the Associated Mean Arterial Pressures Before and after Various Doses of Intravenous L-Nor-Epinephrine in Hypertensive Patients, Before and AFTER ThORACOlumbar Sympathectomy

The pharmacodynamics of the racemic mixture, and lately of the 1-isomer, of nor-epinephrine have been extensively studied. Originally, Bacq concluded from his experiments that nor-epinephrine was similar, if not identical, to Sympathin E (14). Consistent with the concept of Cannon that Sympathin $\mathrm{E}$ had no inhibitory qualities, nor-epinephrine was stated to have no vasodilator effects, and not to be modified in its pressor action by such adrenergic blocking agents as the Fourneau compounds (F933) (15). However, more recent experiments have furnished evidence that nor-epinephrine does have definite, though minimal, vasodilator actions and is locked by the Fourneau compounds (16). This evidence and the recent biochemical data demonstrating the presence of nor-epinephrine in the adrenal medulla and natural lots of epinephrine suggest that it is probably not identical to Sympathin E, but rather that it is an intermediate primary sympathomimetic amine involved in the synthesis of epinephrine (17).

Goldenberg and his co-workers have suggested that hypertensive patients after the administration of 1-nor-epinephrine have a greater response in the systolic and mean arterial pressures than do normotensive subjects (12). In the present study no increased sensitivity to the pressor effects of 1-nor-epinephrine could be demonstrated in preoperative hypertensive patients, as contrasted with normotensive subjects. On the other hand, some hypertensive patients after splanchnicectomy did show a greater increase in blood pressure after small intravenous doses of 1-nor-epinephrine. Furthermore, the preoperative hypertensive patients failed to exhibit the normal reflex slowing of pulse rate during their hypertensive responses to intravenous 1-nor-epinephrine. This phenomenon resembled that noted in a recent investigation of intravenous epinephrine in this laboratory (13). Barcroft (18) and Goldenberg (12) also found a definite slowing of the pulse rate in normotensive subjects receiving infusions of 1-nor-epinephrine. However, in some hypertensive patients, Goldenberg found an increase in pulse rate as well as in cardiac output, which he attributed to emotional factors sufficient to cause the endogenous release of epinephrine, a known antagonist to nor-epinephrine. The failure of normal deceleration of the pulse rate in hypertensive patients during pressor responses to intravenous sympathomimetic amines again raises the question whether there is an autonomic imbalance in patients with uncomplicated essential hypertension (19).

\section{CONCLUSIONS}

1. Intermittent intravenous doses of 1-nor-epinephrine produce single phase hypertensive re- 
sponses with proportionate rises in both systolic and diastolic blood pressure.

2. There is no significant difference between the blood pressure responses to 1-nor-epinephrine in normotensive subjects and in patients with essential hypertension before sympathectomy.

3. Thoracolumbar sympathectomy does not alter strikingly the pressor responses of hypertensive patients to intravenous doses of 1-nor-epinephrine, although some hypertensive patients early after splanchnicectomy may show increased sensitivity to the smaller doses.

4. The pulse rate responses of normotensive and hypertensive patients to intravenous 1-norepinephrine are significantly different. During the hypertensive response to 1-nor-epinephrine, there is a definite slowing of pulse rate in normotensive subjects which fails to occur in the preoperative hypertensive patients. After thoracolumbar sympathectomy, the pulse rate of hypertensive patients slows normally during hypertensive responses to intravenous 1-nor-epinephrine.

\section{BIBLIOGRAPHY}

1. Oliver, G., and Shafer, E. A., On the physiological effects of extracts of suprarenal capsules. J. Physiol., 1895, 18, 230.

2. Elliott, T. R., The action of adrenalin. J. Physiol, 1905, 32, 401.

3. Barger, G., and Dale, H. H., Chemical structure and sympathomimetic action of amines. J. Physiol., 1910, 41, 19.

4. Loewi, O., Über humorale Übertragbarkeit der Herznervenwirkung. I. Mitteilung. Arch. ges. Physiol., 1921, 189, 239.

5. Loewi, O., UUber den Adrenalingehalt des Säugerherzens. Arch. internat. de pharmacodyn. et de thérap., 1937, 57, 139.

6. von Euler, U. S., A specific sympathomimetic ergone in adrenergic nerve fibers (sympathin) and its relations to adrenaline and nor-adrenaline. Acta physsiol. Scandinav., 1946, 12, 73.
7. Tullar, B. F., The resolution of $d l$-arterenol. J. Am. Chem. Soc., 1948, 70, 2067.

8. Luduena, F. P., Ananenko, E., Siegmund, O. H., and Miller, L. C., Comparative pharmacology of the optical isomers of arterenol. J. Pharmacol. \& Exper. Therap., 1949, 95, 155.

9. Tullar, B. F., The separation of $l$-arterenol from natural U.S.P. epinephrine. Science, 1949, 109, 536.

10. Goldenberg, M., Faber, M., Alston, E. J., and Chargaff, E. C., Evidence for the occurrence of norepinephrine in the adrenal medulla. Science, 1949, 109, 534.

11. Holton, P., Nor-adrenaline in adrenal medullary tumors. Nature, 1949, 163, 217.

12. Goldenberg, M., Pines, K. L., Baldwin, E. deF., Greene, D. G., and Roh, C. E., The hemodynamic responses of man to nor-epinephrine and epinephrine and its relation to the problem of hypertension. Am. J. Med., 1948, 5, 792.

13. Judson, W. E., Culberston, J. W., Tinsley, C. M., Litter, J., and Wilkins, R. W., The comparative effects of small intravenous doses of epinephrine upon arterial pressure and pulse rate in normotensive subjects and in hypertensive patients before and after thoracolumbar sympathectomy. J. Clin. Invest., 1950, 29, 1405.

14. Bacq, Z. M., La pharmacologie du système nerveux autonome, et particulièrement du sympathique, d'après la théorie neurohumorale. Ann. de physiol., 1934, 10, 467.

15. Melville, K. I., The antisympathomimetic action of dioxane compounds (F883 and F933), with special reference to the vascular responses to dihydroxyphenyl ethanolamine (arterenol) and nerve stimulation. J. Pharmacol. \& Exper. Therap., 1937, 59, 317.

16. Wells, J. A., and Rall, D. P., The influence of N-(2bromoethyl)-N-ethyl-1-naphthalene-methylamine on the vasopressor response of a series of amines. Federation Proc., 1948, 7, 264.

17. Blaschko, H., The activity of 1(-)-dopa decarboxylase. J. Physiol., 1942, 101, 337.

18. Barcroft, H., and Konzett, H., Action of nor-adrenaline and adrenaline on human heart rate. Lancet, 1949, $1,147$.

19. Patek, A., and Weiss, S., The tonus of the autonomic nervous system in arterial hypertension. New England J. Med., 1931, 205, 330. 